\section{Does implicit speech in same-different decisions extend to nonsense forms?*}

\author{
STUART T. KLAPP and DONNA M. BISCHOFF \\ California State College, Hayward, California 94542
}

A previous study (Klapp, 1971) demonstrated that response latencies for same-different decisions involving printed words and numbers depend on the number of syllables needed for pronunciation. In the present experiment, Ss first learned to associate one- or two-syllable words to nonsense form stimuli. After extensive overlearning, the Ss were transferred to a same-different decision task involving these nonsense forms. Latencies were independent of number of syllables in the learned response. This was interpreted as showing that the Ss did not use the responses to mediate their same-different decisions, in contrast to the apparent implicit pronunciation for decisions involving printed words and numbers.

A previous paper by one of the authors (Klapp, 1971) reported that reaction time to determine whether two visually presented words are same or different depends on the number of syllables required to pronounce the words. The number of letters per word was not confounded with number of syllables. Similar results were obtained for two-digit numbers requiring two, three, or four syllables to pronounce (e.g., 14, 28, and 37). These findings suggest that a speech-like process is involved in making these same-different decisions. This conclusion seems strange when one considers that, had the Ss been unable to read, they still should have been able to detect differences in the symbols without use of the corresponding linguistic representation. In the present investigation, we ask what would happen if $S s$ were to make same-different decisions for nonsense forms rather than words and numbers. Would Ss use verbal associates to the nonsense forms in a manner analogous to the use of verbal representations for words and numbers? There is some reason to suspect that this might occur. Colegate and Eriksen (1970) had Ss learn verbal responses to nonsense forms and then presented these forms tachistoscopically in a memory task. Those Ss who had learned one-syllable responses showed better retention than did Ss who had learned three-syllable responses. The authors attributed this finding to an implicit naming response. Although their retention paradigm is quite different from the reaction time paradigm being considered here, their findings suggest the possibility that an

*This research was supported, in part, by Institutional Grant Funds for the Advancement of Science from the National Science Foundation. The authors wish to thank Mr. Procopio Calado, who prepared the photographic slides. effect of number of syllables in the learned response might be observed here as well.

\section{METHOD \\ Design}

The experiment consisted of two phases: a paired-associate learning phase in which Ss received extensive training in making verbal responses to nonsense form stimuli, and a same-different judgment phase using these nonsense forms. If Ss use the learned responses in making these judgments, then sets of forms to which two-syllable responses had been leamed should yield longer reaction times than sets of forms to which one-syllable responses had been learned. Each S learned one-syllable responses to some forms and two-syllable responses to other forms, so that the critical comparison is within-S. Assignment of particular responses to particular nonsense forms was balanced across Ss such that each particular nonsense form would be paired equally often with one- and two-syllable responses. In addition to the 16 experimental Ss who received paired-associate learning, there were 16 control Ss who participated in the same-different judgment phase only.

\section{Subjects}

The Ss were students at California State College, Hayward, who participated in order to fulfill a course requirement. This was the population in which an effect of syllables on same-different reaction time had been observed for words and numbers (Klapp, 1971). Alternate Ss were assigned to experimental and control conditions in the order in which they reported for the experiment.

The 10 nonsense forms were selected to have no apparent associates in the authors' judgment, although this was not considered to be critical, since new associates were to be learned in the experimental condition. 1 Response words were selected from the five-letter one- and two-syllable words for which a difference in decision latency had been found previously (Klapp, 1971). The words used were: clear, false, heard, learn, taste, color, fifty, happy, labor, and table.

\section{Paired-Associate Learning}

Experimental Ss were taught the appropriate responses to the nonsense form stimuli by a standard paired-associate learning procedure, using a Stowe memory drum with 2-sec presentation of the nonsense form alone, followed by 2 -sec presentation of both nonsense form and response word. Each of four different lists of form-word pairs was used with four Ss. These lists were generated by randomly dividing the 10 nonsense forms into two sets of five and then by pairing each set of forms with one-syllable words twice and with two-syllable words twice. Memory-drum tapes contained three different random orders of the list of 10 form-word pairs. Initial training was carried out to a criterion of three successive correct recitations of the list of 10 pairs, which required an average of 15 repetitions of the list. This initial training was followed by a 5-min rest interval and then by $30 \mathrm{~min}$ of overlearning under instructions to reduce response latencies which were not actually recorded. From time to time, "feedback" on improvement in response latencies was provided. At the end of this first session, Ss were reminded to return on the following day, at which time an additional $15 \mathrm{~min}$ of overlearning under the same conditions was provided.

Control Ss received no paired-associate learning and were tested immediately in the same-different phase when they reported for the experiment. Although it might have been desirable to provide learning with irrelevant stimulus forms, as a courtesy to the Ss this was not done because of the unpleasantly long learning procedure. All Ss, however, volunteered for the experiment after an announcement indicating that $2 \mathrm{~h}$ on successive days would be involved.

Same-Different Response Latencies

The two nonsense forms to be judged same or different were presented simultaneously by projection, with a 7.4-deg horizontal and 2.6-deg vertical separation. Both forms in each pair had been associated with response words of the same number of syllables. Two blocks of 6 
practice and 80 scored trials were given. The $\mathbf{S}$ responded by pressing a button only when the two forms were the same during one block of trials, the first block for half of the Ss. Then, for the other block, responses were to be made only when the forms were different. During each block of trials, pairs of forms which were the same or different and for which one- and two-syllable responses had been learned appeared in random order. Four different random orders were used. The equipment and timing details have been described elsewhere (Klapp, 1971 ). Instructions emphasized that response latencies were recorded, and encouraged Ss to "respond as quickly as possible while still avoiding errors."

\section{RESULTS AND DISCUSSION}

The rate of false positive responses as a percentage of the possibilities for making such errors was $0.8 \%$ for same responses and $3.0 \%$ for different responses. No errors of response omission were anticipated or observed, since stimuli remain in view for 3 sec. Response latencies did not differ significantly between experimental and control groups $[t(30)=.73$, $p>.10]$. Overall average latency was $474 \mathrm{msec}$, compared to $695 \mathrm{msec}$ when printed words were used (Klapp, 1971, Experiment 3). The shorter latency for nonsense forms is consistent with the assumption that response words were not used with nonsense form stimuli, although this interpretation does not necessarily follow because only one symbol was presented compared to the five letter symbols of the words. The more critical test for implicit speech concerns the prediction that response latencies should be longer for forms to which Ss had learned two-syllable rather than one-syllable responses. As is apparent in Table 1 , there is no support for this prediction. A small and nonsignificant $[F(1,15)<1]$ contrary tendency was observed. If this finding is accepted at face value, it indicates that Ss do not use implicit speech in making same-different decisions involving nonsense forms.
Table 1

Mean Response Latencies in Milliseconds Mean Response Latencies in Miseconds

\begin{tabular}{|c|c|c|c|}
\hline \multirow{2}{*}{$\begin{array}{c}\text { Decision } \\
\text { Type }\end{array}$} & \multicolumn{2}{|c|}{$\begin{array}{l}\text { Experimental Ss } \\
\text { Syllables in } \\
\text { Learned Response }\end{array}$} & \multirow{2}{*}{$\begin{array}{c}\text { Contro } \\
\text { Ss }\end{array}$} \\
\hline & 1 & 2 & \\
\hline $\begin{array}{l}\text { Same } \\
\text { Different }\end{array}$ & $\begin{array}{l}457.8 \\
474.2\end{array}$ & $\begin{array}{l}456.4 \\
474.1\end{array}$ & $\begin{array}{l}474.9 \\
490.1\end{array}$ \\
\hline $\begin{array}{l}\text { Condition } \\
\text { Mean }\end{array}$ & \multicolumn{2}{|c|}{465.6} & 482.5 \\
\hline
\end{tabular}

However, this conclusion is based on accepting null results and therefore must be carefully examined. Two specific objections can be raised, and these will be considered in turn.

First, consider the possibility that this experiment might not have been sensitive enough to detect a substantial syllable effect had one existed. The present experiment should have been more powerful than the reference experiment (Klapp, 1971), in which a significant effect was found. Both experiments used a within-S design, but the present experiment used more Ss (16 rather than 12) and more trials (160 rather than 112). Furthermore, the largest difference by which latency for two syllables exceeded latency for one syllable for any one $S$ was 21 msec, which is less than the average across is ( $23 \mathrm{msec}$ ) in the reference experiment. Thus, it seems reasonable to conclude that any true effect of syllables under the conditions of the present experiment must have been considerably less than that occurring in the reference experiment.

A second possible objection to concluding that implicit speech is not present when making same-different judgments involving nonsense forms could be based on the assumption that Ss did use verbal responses, but they did not use the particular responses which were presented in the paired-associate learning phase. If this were the case, the use of verbal process would not have been detectable by our method. However, this seems rather unlikely. A monumental amount of overlearning was provided, far more than was used by Colegate and Eriksen (1970) with positive results for retention of nonsense forms. Furthermore, one would expect that the newly learned associates would at least have interfered with the responses actually used, even if new responses did not replace older habits. This would lead to the prediction that overall latencies should be longer for experimental than for control Ss who did not receive paired-associate learning. There is no support for this prediction, and, in fact, latencies tended to be nonsignificantly longer for control Ss.

Thus, it appears reasonable to conclude that no implicit verbal activity is involved in making same-different judgments for nonsense forms, a conclusion which is in agreement with the Ss' introspective reports. If this conclusion is correct, then why does implicit speech seem to occur for language symbols? These symbols presumably could have been treated as nonsense forms and decisions made without use of verbal representations. It is possible that the implicit speech with words and numbers slows the decision process but cannot be inhibited, since most adults seem to be unable to see a word without reading it.

\section{REFERENCES}

COLEGATE, R., ERIKSEN, C. Implicit speech as an encoding mechanism in visual perception. American Journal of Psychology, 1970, 83, 208-215.

KLAPP, S. Implicit speech inferred from response latencies in same-different decisions. Journal of Experimental Psychology, 1971, 91, 262-267.

\section{NOTE}

1. The nonsense forms were chosen from the abstract reasoning subtest of the Differential Aptitude Tests published by the Psychological Corporation, 304 East 45th Street, New York, New York 10017. With reference to Form $L$ of this test, the nonsense forms chosen were: Question 2 , first item in problem set; $Q .4$, third in problem set; $Q .5$, first in problem set: $Q .7$, first in problem set; Q. 20, first in problem set; $Q .25$, third in problem set; Q. 29, second in problem set; $Q .30$, thind in problem set: $Q$. 44, fourth in problem set; and $Q .49$, first in answer set.

(Received for publication November 29 , 1971.) 